\title{
Who Opposes Climate Regulation? Business Preferences for the European Emission Trading Scheme
}

\author{
Federica Genovese \\ fgenov@essex .ac .uk
}

\author{
Endre Tvinnereim \\ endre.tvinnereim@uni.no
}

June 19, 2018*

\begin{abstract}
When do firms oppose international climate policy? Existing work often assumes that firms disapprove of climate regulation due to the immediate costs of compliance. We claim that if policy is implemented gradually, private preferences for climate policy vary as a function of its progressive stringency. That is, supportive views may rise in the initial phase of the policy, while opposing views may emerge as the policy becomes more stringent. We also argue that emissions of individual companies, as well as emissions levels in their respective sectors, influence corporate positions on these two dimensions. We test our argument with new corporate survey data on the European Union Emission Trading Scheme (EU ETS). We find that firms' views on the performance of the EU ETS vary based on whether they concentrate on the policy's current state or its future, more stringent development. Moreover, we find that individual firm and sectoral emissions correlate with support for the early-stage, more lenient version of the ETS, but that high-emission firms are more interested in disinvesting and relocating if the ETS becomes stricter. Our findings imply that both firm and sectoral organization can constrain environmental regulation, and that domestic compensation, especially at early stages, can have important effects on the success of climate policy.
\end{abstract}

\footnotetext{
${ }^{*}$ We thank Stig Schjølset and Anders Nordeng at Thomson Reuters for data access, and Roman-Gabriel Olar and Luis Everdy Mejia for research assistance. We are also grateful to Michaël Aklin, Jacob Copas, Iza Ding, Julia Gray, Megan Mullin, Jakob Skovgaard, Paul Tobin, Simon Weschle, the editor Axel Dreher, two anonymous reviewers, and the APSA 2015, EPSA 2016, IPSA 2016 and the 2017 InoGov Durham workshop participants for very useful feedback.
} 


\section{Introduction}

Environmental regulation is an important subject of international cooperation and a major source of political debate. Political interest in this area is driven by the fact that crossnational environmental policies often impose direct burdens on domestic companies, while benefits are frequently diffuse. Against this light, private companies are often assumed to oppose international environmental policy because this increases their costs of production. However, some evidence suggests that firms' interests may vary: while some firms have opposed environmental regulation, others have embraced it.1

This inconsistency is the main problem tackled in this paper. Overall, it remains underexplored how firms relate to the diffusion of environmental policy and why. Clarifying these preference patterns is important, since policymakers need to know when domestic opposition to environmental policy is more likely to emerge. We propose a way to think about why firms may systematically support or oppose environmental policy that is gradually introduced across different countries. To the extent that a policy is a burden due to high progressive costs of adjustment, a company may be more inclined to free-ride or oppose the policy. To the extent that environmental policy creates opportunities such as an increase of rents or a market advantage while averting more onerous and direct regulation, the benefits of the policy may trump the adjustment costs. We posit that whether benefits or costs prevail in firms' positions on environmental policy depends on whether firms internalize protective or competitive aspects of the policy. We conjecture that the gradual diffusion of environmental policy can be more protective of regulated firms at the more lenient initial

\footnotetext{
${ }^{1}$ The Guardian. 2015. More Big Businesses Push For Stricter Environmental Regulations. http://www. theguardian.com/sustainable-business/2015/feb/04/business-manifesto-sustainability-guidelines-climate-policy.
} 
stages. Consequently, companies that focus on the laxer state of a new policy may see the beneficial aspects of complying. However, as the implementation of the policy becomes more stringent, companies may become more anxious about the long-term costs of regulation. This may eventually lead to firms escaping compliance, for example, by relocating to countries with weaker regulation.

We argue that these policy preferences are best explained by the characteristics of individual firms and the sectors to which they belong. Political economy research is increasingly interested in the firm-level politics of globalization, and many scholars now accept that in the liberalized global economy heterogenous firms tend to behave as autonomous actors following their intra-industry incentives (Helpman et al., 2004). Along these lines, some research has suggested that sectoral positions on regulation may not be consistent with the most influential firms' preferences or may not be systematic at all (Baldwin and Forslid, 2010. Kim, 2017). We contend that, in the context of international environmental regulation, it is still useful to account for both firm- and sector-level of preferences, because environmental policy often targets both individual firms and industrial organizations, so both should influence firms' preferences for environmental policy, although not necessarily in the same way. Firms should generate their corporate position based on their individual comparative advantages, but this position should also be tailored to the sector they belong to, which may be more or less constrained for structural and political reasons. Hence, firms' characteristics may motivate opposition for a policy, but sectoral characteristics may equally constrain such opposition.

We test our argument in an international environmental policy setting that involves both firm- and sector-level action. We concentrate on cap-and-trade, a market-based en- 
vironmental regulation that is currently implemented in several countries and has sparked diverging political preferences across most of them.2 Our case is the European Union Emission Trading Scheme (EU ETS), which is the biggest regional system for trading greenhouse gas emission allowances. Our principal data source is the proprietary Thomson Reuters Point Carbon annual opinion survey of carbon market participants, which includes several numerical and qualitative measures of companies' opinions on cap-and-trade (Røine et al. 2008; Dimantchev et al., 2013). This exclusive dataset provides a unique opportunity to study the policy attitudes of a representative sample of EU ETS companies across time, countries, sectors, and firms of varying sizes.

Our analyses suggest a number of important findings for international political economy research. First, we find that firms' positions towards international climate change regulation vary along its time dimension. Specifically, a statistical analysis of the companies' assessment of the EU ETS indicates that the discussion over carbon trading is loaded on two axes: On the one hand, a sentiment towards cap-and-trade is concentrated over the questions of efficiency and maturity of the initial, more lenient state of the policy. On the other hand, concerns regarding future policy costs emerge with respect to the stringency of the $\mathrm{CO}_{2}$ price in the long run and the possibility of relocation.

Beside establishing this duality in views on the EU ETS, we also find that both firmand sector-level emissions affect the positions over the two dimensions. At the firm level, high-emission companies are more likely to support the EU ETS at its initial stage, but they are also more likely to consider moving their production abroad in the longer run if $\mathrm{CO}_{2}$ prices may rise. At the sector level, we find that higher volumes of sectoral emissions are

\footnotetext{
${ }^{2}$ Carbon trading has arguably stimulated more disagreements than less flexible top-down measures, such as a carbon tax, or more discretionary measures, such as voluntary carbon standards.
} 
also associated with more support for the initial stage of the EU ETS. Additionally, we find that higher sectoral emissions negatively influence firms' considerations of disinvestment and relocation. Consequently, while this implies that complying firms in relatively less polluting sectors are more likely to express an interest in relocating if cap-and-trade becomes more stringent, it also means that firms in high emission sectors may juxtapose regulation in less explicit ways, e.g., passing costs down to consumers.

Substantively, the paper indicates that gradual climate policy triggers a range of distinguishable positions among regulated actors, and that while individual firm characteristics are crucial determinants of policy preferences, aggregated sectoral characteristics are equally important considerations that policymakers should take into account. More generally, our findings shed light on the distributional consequences of environmental regulation, and provide first-hand evidence of how firms support costly short-term environmental policies in order to hedge more costly policies in the long run (Hacker and Pierson, 2002; Meckling, 2015). Furthermore, our investigation has implications for international organization in policy areas that encompass heterogenous private actors. For example, our paper speaks to the literature on the effect of policy timing and institutional design on firms' preferences for environmental cooperation (Pierson, 1993). Lastly, our paper contributes to the literature on the winners and losers of international regulatory designs by highlighting their potential behavior under different - internal or sectoral - pressures (Mattli and Woods, 2009; Büthe and Mattli, 2011). 


\section{Theoretical Framework}

The number of actors involved in the implementation of international environmental regulation is usually large, and so is the variety of preferences for the design of environmental regulation. Understanding these contrasting preferences is important because it helps identifying which domestic actors systematically accept costly policy adjustments and which instead are more likely to oppose them. Consequently, mapping the conflict across industrial actors is critical to understand the conditions under which compensation could persuade sensitive firms to accept the terms of environmental regulation. In this section we address the

elements that help us identify these sensitivities. We first discuss the multidimensionality of firms' opinions on international environmental policies that are implemented gradually, and we examine how firms' structural characteristics may drive these opinions. We then propose two sets of testable hypotheses with regards to winners and losers of Europe's ETS.

\section{Multidimensional Preferences: Today's Benefits, Tomorrow's Costs}

A prevalent assumption in the study of international environmental regulation is that economic actors facing material costs from policy adjustment should oppose the domestic implementation of that policy. Under this assumption, companies become uncooperative as a function of the increasing competition over the rents of policy making (Meckling, 2011, Whaller and Whitehead, 1994). This conjecture has spurred much empirical inquiry, but has also generated mixed findings that suggest that benefits may as well dominate firms' utility for policy compliance (Bernauer et al., 2013, Böhmelt, 2013). After all, international environmental regulations can generate private economic benefits by creating first-mover advantages and revealing information that rewards the suppliers of high environmental quality 
products (Ambec et al., 2013). Firms may also see environmental regulation as a competitive edge if the costs they face are lower than those of their international competitors Meckling, 2015). Similarly, market investigations have suggested that, given high rates of productivity, a firm's utility to provide environmental goods is likely to increase. These insights, however, have concentrated on the economic implications rather than the political motivations behind firms' preferences for pollution control. Despite a few exceptions (Meckling, 2011, 2015; Szakonyi and Urpelainen, 2014), the rationales that drive private actors' position on environmental regulation are still largely understudied.

Research that has explored the political mechanisms behind support for environmental regulation indicates that lobbying efforts can let firms extract favors in order to protect their services. For example, some businesses may lobby for particular types of regulation to hedge against the risk of facing less favored policy options $3^{3}$ Analogously, companies that signal to politicians the boundaries of accepted regulation can exchange the promise of international compliance with domestic political benefits (Auld et al., 2008). Environmental regulations may also allow firms to access foreign markets, enabling them to emphasize their contributions to society while safeguarding trade interests (Urpelainen, 2010). These justifications for policy support have hardly been integrated in comparative studies of business preferences for environmental policy, which still largely focus on the immediate economic costs of policy adjustment (Murphy, 2004, Cao and Prakash, 2010). This is in part due to the simplifying, unidimensional benefit-cost assumption often made to distinguish companies that face more or less material burdens. It is also related to the difficulties in measuring compliance benefits,

\footnotetext{
${ }^{3}$ In the words of Meckling (2011), "to some industries, such as the oil, electricity, and energy-intensive manufacturing ones, engagement with climate policy is about managing and containing regulatory risk. Other industries including low-carbon technology producers, financial services providers, and investors can seize opportunities under a market-based climate regime" (p. 23).
} 
especially if adopting environmental regulation does not automatically imply an increase in material returns (Perkins and Neumayer, 2012). Furthermore, the definition of benefits is relative to the nature of the policy instrument under analysis. For instance, acting 'green' may credibly benefit firms if environmental policy creates discriminatory advantages to the targeted firms (Lyon and Maxwell, 2008; Genovese et al., 2017).

What is also usually understated in this literature is the variation in regulatory benefits and costs when governments decide to progressively implement environmental regulation. Policymakers may try to anticipate firms' opposition by proposing policies that prevent an immediately negative reaction. One way to achieve this is through coordinating a gradual policy that first nominally 'prepares' the regulated actors, and then progressively aims at the actual environmental goal. Consequently, in the early stages of an international environmental policy, several regulatory incentives may be in place that could lead firms to support regulation. For example, for a policy such as the EU ETS, European governments initially decided to automatically assign 'free' emission permits to a large number of European firms. This meant that the EU ETS constituted a form of subsidy and in some cases made complying firms more competitive than their foreign counterparts. Consequently, some EU companies may have supported some form of cap-and-trade based on these material incentives.

At the same time, as any effective regulatory instrument, the EU ETS was never meant to be without costs. In fact, the European cap-and-trade system was set up as a training market intended to eventually turn into a more stringent scheme. Thus, while the opportunities derived from the initial policy may have benefitted regulated companies in the short run, moving towards a system of more rigid emission caps and costly permits meant that the compliers would have faced a potentially significant burden in the long run. After all, 
pricing mechanisms such as emission trading create weaker favorable constituencies than other policies such as renewable energy subsidies (Meckling et al., 2015). Accordingly, the more stringent EU ETS was meant to tackle a specific group of actors, thereby eventually creating sets of concentrated losers (Olson, 1965).

This does not exclude the parallel emergence of pro-EU ETS opinions. In fact, the creation of the market in emission permits through the EU ETS also provided the grounds for a pro-policy lobby including banks, fund managers, exchanges, consultants, project developers, information providers, and other actors with a stake in functioning carbon markets. Such actors typically also have interests in higher carbon prices, and thus constitute additional pressure groups in favor of stronger reduction targets - arguably a coalition combining financial services and environmentalists (Paterson, 2012). Unlike regulated polluters, and especially large emitters, these groups should have opposed the more 'inefficient' piloting years of the EU ETS, awaiting for the more stringent phase for their own benefits.

Following this reasoning, we argue that short-term opportunistic considerations and long-term economic concerns could usefully be seen as two distinct dimensions of opinions over gradually introduced environmental policies such as the EU ETS. Regulated polluters may embrace an emission trading scheme that generates monetary opportunities from compliance, while they should express more opposition towards a market raising economic constraints. Furthermore, these views may vary across firms, and in what follows we argue that the characteristics of individual companies as well as their sectors should predict opinions regarding the short- versus long-term aspects of the EU ETS. 


\section{Linking Preferences to Firm and Sector Characteristics}

If cost anticipation and strategic opportunities affect corporate sentiments towards a policy instrument such as cap-and-trade, we examine whether these sentiments vary across firms with different structural characteristics. On the one hand, some scholars maintain that environmental regulation - like other reforms in a global market economy - strengthens the forces of competition and empowers firms with the greatest flexibility and market skills (Fernandez and Rodrik, 1991). Along these lines, large companies are generally more capable of adjusting to international environmental regulation, and thus gain an advantage over smaller firms once a new policy is agreed upon (Venkatachalam, 2008).

On the other hand, some scholars claim that the politics of environmental regulation only truly materialize on sectoral grounds (Kim et al., 2016). If a policy is designed to punish pollution and reward 'clean' companies, it is in the firms' best interest to collectively organize preferences at the sectoral level. According to this view, the sector is the most efficient level of mobilization, since it is the natural point of aggregation among firms producing similar products and confronting similar challenges (Brooks and Kurtz, 2007). Sectors that are most constrained by an environmental policy should then be associated with more mobilization, which should then lead to a more coherent opposition. Contrastingly, sectors that are least constrained by the policy should be associated with less mobilization, everything else equal.

We argue that both the firm and the sector level of action should influence companies' positions on international climate policy. At the firm level, we believe that whether companies face higher material costs from adjusting to a policy or whether they are more politically suited to reap the benefits of the policy should vary by whether they are large enough to absorb such costs or safeguard such benefits. For example, large polluters such as 
Exxon or Enel could lobby for their specific goals on their own and could push for legislative exceptions that apply only to them. Consequently, they would perceive a climate policy they can more directly shape differently than a smaller and politically weaker polluter.

At the same time, features at the sector level should also influence the average firm's policy positions. Sectoral collective action could soften the impact of climate policy by increasing clientelistic provisions that benefit the sector's members at the expense of the general public (Damania et al., 2003). Vice versa, sectoral lobbying could reflect the dimensions in which a new regulation can increase the expected benefits from burden sharing Ostrom, 2010). This implies that the relative standing of a sector within a country is crucial for a firm's ability to influence a climate policy in the short and long run. Thus, both firm and sector characteristics should influence the sentiments of individual companies for a climate policy such as cap-and-trade.

\section{Expectations: Firms' Positions on the EU Emission Trading Scheme}

The case study used to explore our argument is the European Union Emission Trading Scheme (EU ETS). Cap-and-trade, of which the EU ETS is an example, constitutes a type of regulation that sets aggregate limits on the amount of pollution that may be discharged by facilities from one or several industrial sectors. Regulated firms may comply with the law either by reducing their own emissions or purchasing excess permits from other companies that have been able to reduce theirs. Cap-and-trade thus introduces a price on pollution that at least in theory converges on the marginal cost of emission reductions given the environmental ambition set by policymakers. In this way, companies with high compliance costs may postpone reductions while those with low (or negative) costs gain financial incentives 
to reduce more than they would under direct regulation.

Importantly for our theoretical reasoning, the EU ETS is a policy instrument that on the one hand implies private concerns over economic adjustment, but on the other hand has offered significant benefits to firms, because carbon credits in the EU ETS were implemented progressively. Specifically, the EU emission cap was first introduced in 2005 at a relatively unambitious level, and then incrementally tightened to ensure the desired drop in emissions. Initially the EU gave away permits for free to most complying companies. Thus, for some firms this initial phase provided net benefits, in that free permits made them more economically competitive and policy compliance made them more attractive to consumers and investors. Over time, however, EU governments chose to sell more permits at market prices and give fewer away, gradually increasing costs for firms covered by the regulation. As of 2013, an auctioning system for permits kicked in, finally halting profits.

We claim that, thinking about the different stages of the EU ETS policy, complying firms should express different opinions on the cap-and-trade scheme. We posit that, thinking about the initial years of the EU ETS, average compliers should have expressed more supportive opinions for the main features of cap-and-trade. By contrast, perceptions should have changed as a function of the development of the policy. In other words, the average firm should have expressed more anxiety - e.g., more willingness to relocate - as the total number of permits declined along with the share of permits given away for free. Moreover, we think the opinions on the EU ETS are not homogenous across all firms. Consistent with our previous discussion, we claim that the sentiments towards the EU ETS, which should be reflective of the policy's time-varying costs and benefits, would depend on the characteristics of the firms and their sectors. 
Focusing first on firm-level characteristics, we argue that when considering the more lenient version of the EU ETS, firms should think of low adjustment costs and more protection for more polluting companies. Large emitters draw greater benefits from avoiding potentially more demanding policies such as high carbon taxes or facility-level emission standards. Thus, firms discharging more carbon pollution into the atmosphere should have been more supportive of the early-stage EU ETS, which implied windfall profits. By contrast, small emitters should have been relatively less supportive of emission trading, because they saw little to gain from generous caps and low carbon prices.

If we instead consider the more stringent version of the EU ETS, firms' opinions should be substantively different. Deeper emission cuts and an increased long-term carbon reduction ambition represent a move towards a more burdensome policy, which entails higher adjustment costs for the bigger polluters. For these firms, more stringent carbon caps should be linked to worries about pricing and contemplating relocation to other world regions. By contrast, smaller emitters may have more to gain from a stricter ETS.

This discussion leads us to the following first set of firm-level hypotheses. First, in a context in which the ETS is still a lenient and modest regulation, we expect that the larger the individual (firm-level) emissions of a company, the more that company would support that version of the ETS. Second and conversely, in a context in which the ETS progresses towards a more stringent regulation, the larger the individual emissions of a company, the more that company should oppose the regulation. Thus, if asked to think of the implications of a more stringent EU ETS, a high-emission company should express worries about future investments and considerations about relocating away from the ETS area.

This said, companies should also relate to carbon prices on the premise of sectoral 
characteristics. More specifically, each sector's carbon intensity may also predict whether and how firms oppose the EU ETS regulation. We expect that more efficient (i.e., less polluting) sectors should be capable of absorbing more ambitious emission constraints, because firms in low-emission sectors have less difficulty in adjusting to cap-and-trade, and their industry should not suffer from more ambitious caps. Conversely, sectors that represent less efficient production chains or more energy-intensive consumption patterns would bear more costs from tighter policy. Thus, firms in high-emission sectors should have supported the EU ETS only at its lenient stage, when all the firms in more polluting sectors remained protected, and should have shown more resistance under more stringent regulation. This, however, does not imply that opposition emerges as a threat of disinvestment or relocation. After all, the average company in higher-emitting sectors may not be more inclined to deal with the policy by means of relocating, because of structural dependence on the territory. Hence, firms in more polluting sectors may have no credibility of threatening to move away because of carbon constraints, despite intrinsically opposing regulation.

This leads us to our second set of sector-level hypotheses. First, in the context of a more lenient ETS, we expect that the larger the emissions of a sector, the more a company within that sector would support the policy. Second, provided an increasing ETS stringency, we expect that firms in high-emission sectors should express less opposition to the policy, i.e., less reference to changing investments and consideration for relocation, due to structural inflexibilities. This expectation is especially contingent on the power sector, the largest emitter across Europe. This sector was especially protected by the initial EU ETS because, on top of windfall profits driven by free permit allocation, customers typically cannot import power from outside of the EU, so its providers could pass on cost to them. Then, despite 
resenting the EU ETS in its more stringent years, the European power sector still has structural reasons for engaging with the policy rather than relocating like more flexible sectors. In sum, while high-emission sectors may still suffer from stricter emission caps, removing investment and threatening relocation may not be credible ways to oppose it.4

\section{Data and Research Design}

We test our theoretical expectations against a new dataset based on the Carbon Market Survey, which is an annual online survey conducted by Thomson Reuters Point Carbon. First fielded in 2007, the Carbon Market Survey has been carried out every year since (Dimantchev et al., 2013). All firms covered by the EU ETS regulation are invited to take part in the survey, based on e-mail addresses from the EU ETS installation registry.5 The sample includes participants from industries regulated by greenhouse gas caps or taxes, financial services, regulators, and emission reduction project developers. Verifiers, NGOs and researchers are also included, although they are a smaller portion of participants.

A qualitative evaluation of the data gives us little reason to believe that the EU ETS firms in the survey are systematically different from those that did not participate. In terms of size, companies ranging from 5 to 400 thousand employees took the 2010 survey, which is consistent with the range of size of enterprises in the European Union in that year ${ }^{6}$ The median size of the firms in 2010 is of 5 thousand employees, which is in the neighborhood

\footnotetext{
${ }^{4}$ Note that our discussion purposefully ignores the preferences that firms may have for implementing no ETS at all. For the European ETS the possibility of abandoning altogether the carbon market is unrealistic. Nonetheless, this is not an irrelevant policy equilibrium in other contexts, and further work may want to elaborate on this potential alternative outcome.

${ }^{5}$ Specifically, up to three e-mail addresses for each covered emitting facility are listed. Participants receive a free copy of the resulting survey report as an incentive to complete the survey.

${ }^{6}$ See Eurostat data on EU structural business statistics at http://ec.europa.eu/eurostat/ statistics-explained/index.php/Structural_business_statistics_overview.
} 
of the average 1,000 employees working in European firms between 2006 and 2010 (see De Massis et al., 2012, p. 50-51). In terms of geographical representation, all EU ETS countries are represented. Also in line with the real-world economic breakdown of the EU economy, a substantive number $(\sim 40 \%)$ of individuals that responded to the 2010 survey worked for government, NGO groups, public administration or consultancy firms, while the rest worked for private business groups, including finance and insurance companies.7

Each annual survey comprises roughly fifty questions and several opportunities for the respondents to express their views on the EU ETS in their own words, to which we will return at the end of the paper. Due to restructuring in the questionnaire, some of the main categories in the first two waves of the survey are missing, so for our analyses we focus only on the survey data between 2009 and 2013 Although the surveys encompass companies that have foreign activities and therefore employees based abroad, our theory focuses mainly on EU firms with political stakes in the EU ETS, so in our main analyses we concentrate on companies that select any of the EU-28 states as their home country! $!^{9}$ Note that the original questionnaire was answered by individuals, and at times by more than one person in the same company. However, our unit of analysis is companies themselves. Due to privacy concerns, firms' names are not available in our data set. Nonetheless, we were allowed to use information elicited through the survey that is specific to each firm to identify similar

\footnotetext{
${ }^{7}$ See Eurostat data on breakdown of economic activities in EU total employment at http://ec.europa. eu/eurostat/web/products-eurostat-news/-/DDN-20171024-1?inheritRedirect=true

${ }^{8}$ Using the post-2008 surveys is also reasonable because it allows us to concentrate on firms' positions during the first commitment period of the Kyoto Protocol and after the recent financial crisis. We need to ignore the 2007 survey because it lacks information on the companies' countries, while the 2008 survey lacks information on sectors. We also ignore the 2014 survey responses because, although we received the data, some questions had different wordings and we do not possess several control variables.

${ }^{9}$ These are: Austria, Belgium, Bulgaria, Croatia, Czech Republic, Denmark, Estonia, Finland, France, Germany, Greece, Hungary, Iceland Ireland, Italy, Latvia, Lithuania, Luxembourg, Malta, Netherlands, Norway, Poland, Portugal, Romania, Slovak Republic, Slovenia, Spain, Sweden, and the United Kingdom. See Figure A.1
} 
groups of firms. This information distinguishes the firm's location, sector and volume of annual emissions given in categories. We grouped firms by these criteria in order to generate a consistent unit of analysis across time and countries.

Table 1 describes the main characteristics of our sample. ${ }^{10}$ The survey respondents range across all the sectors represented by the EU ETS. In terms of emissions, our sample is relatively less representative of power generation and more representative of manufacturing companies compared to the EU ETS. The relative under-representation of power sector respondents may give us confidence that, if we find evidence in favor of the high-emission sector hypothesis, the preferences are not contingent on the power sector only. In terms of the percentage of firms that actually participated in the survey out of all the firms covered by the regulation, the EU ETS regulates roughly $45 \%$ of the total EU GHG emissions as of 201511 Because in 2010 the total GHG emission by EU ETS countries was 4909.5 million tons of $\mathrm{CO}_{2}$ equivalent ${ }^{12}$ and the surveyed companies report a total of 1584 million tons of $\mathrm{CO}_{2}$ emission (Table 1), we deduce that the firms in our survey represent roughly $32 \%$ of the total EU GHG emissions, not far off the actual population. In sum, we have reason to believe that our survey sample is representative of the EU ETS population and should not a priori bias our results.

\footnotetext{
${ }^{10}$ Population data used in this table was gathered from the European Environmental Agency, 2016. See http://www.eea.europa.eu/data-and-maps/indicators/greenhouse-gas-emission-trends-5/ assessment-1, Fig. 4, and http://www.eea.europa.eu/publications/trends-and-projections-2013, Fig. 2.1 (p. 21).

${ }^{11}$ See European Commission brief on the EU ETS at https://ec.europa.eu/clima/sites/clima/ files/factsheet_ets_en.pdf.

${ }^{12}$ See Eurostat data on total GHG emissions for 1990-2015 at http://ec.europa.eu/eurostat/ statistics-explained/index.php/Greenhouse_gas_emission_statistics.
} 


\section{Outcome variables}

Our outcome of interest is companies' positions towards the EU ETS. In particular, we are interested in positions across different, time-varying aspects of this regulation. We identify five survey questions that would seem to capture these short- versus long-term perspectives. Cost Efficiency and Maturity correspond to the participants' level of agreement with two statements regarding the state of the policy as it is: "The EU ETS is the most cost-efficient way to reduce emissions in the EU" and "The EU ETS is a mature market." The response scale for each of these, respectively, is a five-point interval that goes from 1 'Completely disagree' to 5 'Completely agree'. Then, $\mathrm{CO}_{2}$ Reduction is the response to the retrospective question "To what extent has the EU ETS caused your company to reduce its own emissions?". Here the response scale includes 1 for "the EU ETS has not yet started causing emission reductions in our company', 2 for 'the EU ETS has not caused emission reductions in our company', and 3 for 'the EU ETS has already caused emission reductions in our company'. Finally, we identify two questions related to the long-haul implications of the EU ETS. Salience of $\mathrm{CO}_{2}$ price is the response to the question "How important is the long-term carbon price (e.g., in 2020) for new investments in your industry?", where the answers are scaled from 1 'No importance' to 3 'Decisive factor'. Moreover, Relocation is based on the question 'Has your company considered moving production outside the EU ETS area because of carbon costs?' and is scaled between 1 for 'Yes, have already moved production' to 4 'No' 13

\footnotetext{
${ }^{13}$ One may worry that the different wording of these survey items - i.e., that some require comments on statements and some require answers to questions - may affect the nature of the responses. Consequently, we may be pooling subjective and objective responses rather opinions on different temporal aspects of the EU ETS. While we cannot completely rule out this concern, we think all responses are in part subjective because they all require an interpretation of firms' ideal policy levels and preferred regulatory uncertainty. Also, in the open comment answers (formulated as "If needed, please expand on your answers here") we
} 
All these responses include a 'No opinion/Don’t know' option. Summaries in the online Appendix available at this journal's website indicate that these categories are not negligible in magnitude, but are also not systematically selected. Thus, these data can be cautiously treated as missing at random. It is reassuring that additional regressions show that nonresponses are not correlated with the explanatory variables under consideration and do not disrupt the correlations predicted by our theoretical models.

To use the response data, we need to transform it at the unit level of analysis. This is because the data was accessible to us under the condition that we would not reveal the identity of the individuals nor their respective firm in the survey. We would also not release information that might lead to the identification of individual firms or persons. This means that anonymizing the original individual data does not fulfill the condition as one could still potentially identify the firm of an anonymous individual if such firm were the only one in given country at given time to emit X amount of GHG in a specific sector. Consequently, our terms of agreement with Thomson Reuters Point Carbon were that we would use companies grouped by similar traits as the unit of analysis.

In this regard, we collapsed the values of the responses taking the mean of all the values of the most similar companies within each country, year and sector. For example, for all British, small emission (e.g., less than 500,000 GHG tonnes) companies in the construction sector in 2009, we take the mean of the indicated answers. The answers are scaled so as to assign lower values to more hesitant positions (e.g., more conservative preferences) and higher values to more proactive positions. We round the means downwards, to make sure we anchor

find no evidence that the questions were systematically interpreted as objective versus subjective questions. For example, to the presumably more objective question on the possibility of relocation, a 2012 respondent commented, "I think carbon leakage is a daily threat." Similarly, to the question on the importance of $\mathrm{CO}_{2}$ price for future investments, another respondent wrote, "I suspect we will be heavily influenced in the future". These responses appear as subjective rather than factual statements. 
the responses to lower values, which we expect to have a strong predicting power. Finally, we dichotomize these five variables to make our statistical interpretation more intuitive. We code as 1 responses that denote partial and full agreement with the statements that the ETS is cost-efficient and mature (>3 in the original 1-5 scale) as well as claims that the ETS has caused reduction in GHG emissions (3 in the 1-3 scale), that $\mathrm{CO}_{2}$ price is a decisive factor for long-term investments (3 in the 1-3 scale), and that the firm is considering or planning for relocation ( $>1$ in the $1-4$ scale). The rest we code as 0 . These binary variables are relatively well-balanced among high and low emission companies. ${ }^{14}$

\section{Explanatory variables}

In order to test our hypotheses, we require indicators of emission levels of firms and sectors. For the firms, we rely on self-reported levels of GHG in $\mathrm{CO}_{2}$ equivalents from the questionnaire. The five categories that each firm can select are: $<500,000$ tonnes; 500,000 - $1 \mathrm{M}$ tonnes; 1 - 5 M tonnes; 5 - $10 \mathrm{M}$ tonnes; and >10 M tonnes. For interpretation purposes, we generate the binary variable Firm: high $\mathrm{CO}_{2}$ emitter that takes the value of 0 if the grouped companies selected a category below 1 million tonnes, and 1 for anything above that threshold. However and as we show below, the results are virtually unchanged if we employ the variable Firm: $\mathrm{CO}_{2}$ emissions, which corresponds to the original Point Carbon scale.

Unfortunately the data do not permit us to distinguish between firms based on levels of greenhouse gas intensity - that is, the emissions associated with each unit of output - as we

\footnotetext{
${ }^{14}$ In terms of how sensitive the manipulated variables are to the cut-points, analyses in the online Appendix available at this journal's website (Table A.4 show that the five variables measured on the original scales have similar patterns (i.e., are loaded on the same factors) as the dichotomized variables. Similarly, additional regression analyses (Table A.5 indicate that our findings are not sensitive to the cut-points of the binary variables, as we obtain similar results with the outcomes measured on the original scales.
} 
do not have access to firms' names or their specific characteristics. It is thus possible that a high level of emissions could be associated with either an inefficient firm with high carbon intensity or from a large firm with high overall production levels. For our main analyses, we assume that companies with higher emission levels - be they inefficient or large - should be more affected by the ETS, everything else constant. In additional analyses for a subset of the 2010 data (below) we control for proxies of size, to find that the main results remain unaltered.

The dataset does not include sectors' emissions, but it does allow us to identify the following sectors: Power and Heat; Metals; Oil and Gas; Pulp and Paper; Cement, Lime and Glass; Chemicals; Aviation; Food Industry; and Other. We then matched the companies that belong to each of these sectors with external, observational measures on yearly sectoral emissions. Specifically, we used the CAIT World Resources Institute data, which breaks down national levels of sectoral GHG emissions as million tons of $\mathrm{CO}_{2}$ equivalents 15 The values are matched as follows: the Electricity and Heat emission level is assigned to the Power and Heat sector; the Mining and Fuels emission level is assigned to Metals as well as Oil and Gas; the Manufacturing and Construction emission level is assigned to Pulp and Paper, Cement, Lime and Glass, and Chemicals; and Bunker Fuels is assigned to Aviation. Based on these within-country distributions we split each sector's emission level at the national median and generated the dichotomous explanatory variable called Sector: high $\mathrm{CO}_{2}$ emitter. This takes the value of 0 if the grouped companies belong to a sector with yearly emissions below the national median, and 1 otherwise. Once again, our results are essentially similar if we

${ }^{15}$ The WRI data can be retrieved here: http://cait.wri.org/historical/ For the
year 2013, we used the equivalent indicators reported in the International Energy Agency
2015 Statistics, https://www.iea.org/publications/freepublications/publication/CO\$_
2\$EmissionsFromFuelCombustionHighlights2015.pdf (p. 66).


alternatively employ the original continuous variable, Sector: $\mathrm{CO}_{2}$ emissions.

We have described our two main explanatory variables, but evidently there may be other explanations for firms' positions towards the EU ETS. Notably, the economic environments facing each company may affect climate policy assessments. An important factor could be a sector's unit labour cost (ULC), because industries where labour costs are high - due, for example, to high-skill workers or high-end technology - may influence companies' preference for environmental policy ${ }^{16}$ Thus, we assigned the sectoral ULCs to the sectoral categories in our dataset, ${ }^{17}$ and we then dichotomized the yearly values by country, so to create the variable Unit labor cost: high. This variable indicates with a 1 the sectors that have more labour productivity, and 0 otherwise. Furthermore, the level of wealth in a country may affect the way a firm perceives the costs and benefits of market-based environmental policies. Hence, our regression equation includes a measure of $\log$ GDP per capita in current USD, which we collected from the World Bank's World Indicator Database.

There are also domestic political factors that may affect firms' sentiments towards the EU ETS. The institutional environment where the carbon market is implemented may be influential, as distributing and managing emission permits requires a certain bureaucratic capacity that varies across countries. Consequently, we include the variable Regulatory Quality, which is a World Governance Indicator index where low and high values refer to the low and high ability to govern policies for the private sector, respectively. Firms may also become more averse to climate regulation when the implementing governments are more left-wing,

\footnotetext{
${ }^{16}$ The ULC is calculated as the ratio of total labour costs to real output, and it is expressed as the ratio of total labour compensation per hour worked to output per hour worked. See OECD 2015 data at https://stats. oecd.org/Index.aspx?DataSetCode=PDBI_I4\#

${ }^{17}$ We assigned ULC of oil and power to Power and Heat, Metals, and Oil and Gas; ULC of manufacture to Pulp and Paper, Cement, Lime and Glass, and Chemicals; and ULC of transportation and food to Aviation and Food Industry.
} 
if one assumes that left-leaning governments tend to be more focused on environmental protection and coordinated international policy. Consequently, we collected the variable Government Ideology, which measures the partisanship of the incumbent executive using the Schmidt Index of cabinet composition. This is a scalar with values from 1 to 5 , where a strong majority of right-wing parties is coded 1, whereas a majority cabinet of leftwing parties is coded $5 t^{18}$ Finally, private opinions on the EU ETS may also depend on whether the government is simultaneously implementing other climate policies. For example, if the government is pursuing abatement via emission trading while also allowing tax breaks to fossil fuel users, then emission trading may be less worrisome to polluting firms ${ }^{19}$ Hence, we control for the effect of this contrasting policy through the variable Fossil Fuels Fiscal Support. This variable measures the volume of fiscal exemptions or deductions a national government allows to fossil fuel consumers divided by GDP ${ }^{20}$

\section{Analysis}

\section{Patterns in Corporate Opinions on the EU ETS}

Our analysis begins with an exploration of the survey response variables. Our theory suggests that firms should systematically distinguish between short-term opportunities and long-term costs of the EU ETS, and express their policy-related views accordingly. Thus, our first goal is to assess whether the Carbon Market Survey responses show these time-sensitive patterns. One way to do so is to explore differences between opinions across the survey years, given that the ETS was set up to become more stringent after the first introductory phase ending

\footnotetext{
18 Armingeon et al. 2015

19 Genovese et al. 2017.

${ }^{20}$ OECD-IEA Fossil Fuel Support Data. 2015. http://www.oecd.org/site/tadffss/.
} 
in 2012. In fact, our dataset extends to 2013, the year when the EU ETS switched to the auctioning of carbon permits as the principal allocation rule, forcing many covered firms to buy all or most of their permits in the market. So, we start by visually comparing opinions up to and after the enforcement of auctioning.

We calculated the average yearly opinions on the five selected survey items to see whether attitudes toward the EU ETS varied as 2013 approached. Following our theory, we should find opinions related to the initial stage of the EU ETS, thus especially opinions about the 'current' state of the policy, on average more positive in the years preceding the 2013 auctioning phase, because questions that evoke the viability of the policy should trigger more positive sentiments when the policy is less costly. This should be especially the case among the 'winners' of a lax ETS, i.e., high-carbon intensity firms that gain from cheap credits. Then, as the year when the policy becomes more costly (2013) approaches, positive feelings about regulatory efficiency and maturity should plummet, especially among the more committed polluting firms. Vice versa, concerns related to the implications of the future policy, notably related to the long-term $\mathrm{CO}_{2}$ prices and the preparedness to relocation, should be more prominent for high-carbon intensity firms especially when the ETS becomes more stringent, i.e., in the 2013 auctioning year.

Figures 1 and 2 illustrate the trends in the yearly average of each relevant response measured in the original scale. Figure 1 shows the averages for all the responding firms, while Figure 2 shows the averages broken down by low- and high-carbon firms. As predicted, the opinions regarding the efficiency and maturity of the ETS are more positive before 2013 and decrease in 2013, suggesting that on average the EU ETS companies tend to think higher of the laxer policy, presumably because it is cheaper. Opinions turn more negative in 2013 
especially for high-carbon intensity firms, which means that these are less convinced about the efficiency and maturity of the ETS as soon as it turns more stringent, possibly because they are the losers of stricter caps ${ }^{21}$ Regarding firms' opinions on the long-term $\mathrm{CO}_{2}$ price and readiness to relocate, the responses are less conclusive before 2013 and more sensitive in 2013. Again, the sensitivity is more prominent especially among high-carbon intensity firms, as our argument suggests.

While the descriptive evidence is in the direction of our expectations, a more rigorous approach would require a statistical analysis of the different facets of the Carbon Market Survey responses. Unfortunately we do not have enough data at the yearly level to run a set of powerful year-by-year regressions to test our argument. However, we can exploit the different 'time horizons' implied by the questions in consideration, and evaluate in a pooled fashion whether the responses are intrinsically loaded on axes that reflect the short- versus long-term dimensions of the EU ETS (at least as of the 2009-2013 years). So, to verify if such latent dimensions in the corporate views of the EU ETS exist, we perform an exploratory factor analysis over the five survey responses.

The results from the factor analysis are reported in Table 2. We find that the five variables converge on two main dimensions: one concerning the perceived performance of the EU ETS as of the time of the survey, and the other concerning the future implications of the ETS on the respondent's firm. As the loadings show, evaluations of the cost-effectiveness and maturity of the ETS load more prominently on the first factor. The second factor is most strongly associated with the concern of moving operations and, to a somewhat lesser extent,

\footnotetext{
${ }^{21}$ Note that stringency in this case does not necessarily reflect the price level, but rather the share of auctioned permits and the perceived likelihood that the ETS will be around for the long haul, as signaled by the European Commission's long-term target planning.
} 
to the perceived salience of the long-term $\mathrm{CO}_{2}$ price, which we interpret as the dimension of future expectations for carbon trading ${ }^{22}$

In short, the factor analysis establishes relevant multidimensionality in the response variables, which fits the short- versus long-term views on the EU ETS delineated by our argument. We can now move to test our hypotheses calculating the correlations between the survey responses and our firm- and sector-level emission indicators. To make sure we fully capture the distinctions provided by the factor analysis, we use a principal component analysis to create composite scores for the reduced factors in Table 2 . We use these composite scores as the outcome variables of our main regression models, although we also present the regressions of each of the five separate response items for completeness. Our basic statistical model is a generalized linear estimation of the effects of firms' and sectors' emissions (our main predictors) on the outcome variables. We report ordinary least squares estimates that are easy to interpret, although our estimates are robust to non-linear specifications. Our regression equation includes the control variables discussed in the previous section as well as country and time dummy variables to capture within-country heterogeneity and unobserved cross-year trends. We also cluster our standard errors at the country level to address the possibility that the attributes of companies are similar within each country. However, note that the results are qualitatively the same if we cluster the errors at the sector level. ${ }^{23}$

\footnotetext{
${ }^{22}$ The cross-loadings measured by the uniqueness parameter $(\psi)$ indicate for each variable the proportion of the individual variance that is associated with their factors. As the results indicate, opinions on costeffectiveness and relocation are more uniquely associated with the two factors, respectively. This further suggests that the data are divided on two types of positions, which distinctly reflect the dual nature of opinions towards the EU ETS.

${ }^{23}$ One may also wonder whether hierarchical models may be more appropriate given the multilevel structure of our data. Exploratory tests suggest that the hierarchy does not capture much random variance, and neither countries nor sectors seem to have specific group-level effects on firms' opinions. Moreover, our dataset features similar sample sizes across countries. We refer to these additional findings below.
} 


\section{Correlates of Corporate Opinions on the EU ETS}

We start with a discussion of the model for the composite scores of Factor 1, which we interpreted as the latent support for the short-term implications of the EU ETS. The statistical findings are shown in Table 3. The first two columns refer to the results for the first factor score. The first column is a model where the main explanatory variables are the dichotomized variables (Firm: high $\mathrm{CO}_{2}$ emitter and Sector: high $\mathrm{CO}_{2}$ emitter), while the second column is a model with the effects of the original continuous explanatory variables (Firm: $\mathrm{CO}_{2}$ emissions and Sector: $\mathrm{CO}_{2}$ emissions). First, we find that the volume of a firm's emissions is a reliable predictor of the overall satisfaction with the EU ETS. Throughout the two specifications the coefficient for firms' emission levels is positive and statistically significant, which indicates that firms with high levels of emissions are more satisfied with the introduction and workings of the EU ETS as captured by opinions on maturity and effectiveness.

We interpret this result as evidence that the design of the EU ETS as of 2009-2013 was overall more favorable to large emitters than smaller ones. Firms that are generally large may have gained from the ETS notably from their ability to employ specialists in carbon management and trading, thus identifying optimal strategies for complying with the regulation. Furthermore, firms with relatively inefficient, high-emitting processes may see an advantage in the EU ETS in that they are not subject to more demanding environmental regulations such as taxes or facility-level emission limits. By contrast, lower-emitting firms may see the ETS as less than optimal, as facility-level emission limits or even carbon taxes might have provided them with greater competitive benefits ${ }^{24}$

\footnotetext{
${ }^{24}$ Again, the changes over time in attitudes toward the ETS in Figures 1 and 2 support the reasoning that larger firms more positively related to the EU ETS in earlier years, while smaller firms more positively saw
} 
The results in Table 3 are also significant with respect to the sectoral emission levels. We find that a sector's aggregate volume of $\mathrm{CO}_{2}$ has a positive coefficient. So, firms in more carbon-intensive sectors are more likely to express support for the features of the ETS. This is in line with our conjecture that high-emission sectors are more likely to appreciate the benefits provided by the initial implementation of the ETS compared to low-emission sectors.

We run the same type of model on the second set of scores that we calculated for Factor 2, which we interpreted as a proxy for concerns with the future costs of the ETS. The results are presented in columns 3 and 4 of Table 3 , mirroring the setup of the Factor 1 models. With respect to the partial effects of Firm: high $\mathrm{CO}_{2}$ emitter, we find that higher levels of firms' emissions are associated with higher values of the Factor 2 composite variable. Substantively, firms that produce larger volumes of $\mathrm{CO}_{2}$ are more susceptible to the future implications of stronger regulation (e.g., more likely to express considerations about the long-term costs of permits and relocation). The magnitude of this effect is virtually analogous to the effect of a firm's emissions on Factor 1 scores. Thus, this finding supports our claim that, on the one hand, large emitters supported the initial, more lenient state of the EU ETS captured by Factor 1, but, on the other hand, they have credible incentives to elude regulation and relocate if the EU ETS become more stringent in the future.

The sectoral explanatory variable also provides interesting implications for our argument. Our theoretical discussion suggests that, as the EU ETS becomes stricter, highemission sectors may be more intrinsically opposed to regulation but are less likely to express

the EU ETS from 2012 onwards. This trend could conceivably be related to falling carbon prices; however, it can be shown that permit prices do not play a significant role in explaining attitudes toward the ETS in our data. 
interest in relocation, because high-emission sectors tend to be more bound to the territory where they operate. Along these lines, the regressions of Factor 2 indicate that the coefficient of the sector-level emissions variable is consistently negative and statistically significant for both the binary and continuous sectoral variables. In other words, firms in high emission sectors are less likely to be sensitive to the long-term implications of the EU ETS.

This result may be especially driven by the power sector, which is more capable of 'passing through' costs to local consumers and is less exposed to competition from imports. However, further analyses based on the same model suggest that this is not a power sectorspecific finding. In Table 4 we disaggregate the emissions by (1) each category of firms' GHG level, and (2) each sector in our dataset. We find that firm-level emissions are most correlated with support for the current EU ETS (Factor 1) and sensitivity to the more stringent EU ETS (Factor 2) if emissions are above 1 GHG million tons. As for the disaggregated sectors, we find that, while power firms are the most supportive of the EU ETS as of the time of the survey, construction, aviation and food sectors are significantly less supportive, possibly because some firms in these sectors were less protected by the EU ETS grandfathering and more exposed to foreign competition, even in the regulation's initial years. Moreover, we find that the emissions of the power sector firms as well as oil and aviation firms are negatively correlated with Factor 2. We interpret this to mean that these sectors do not pretend to be able to consider disinvestment or relocation if the ETS were to become more stringent, while metals, construction and food companies are more likely to leave as the policy progresses. This is also evidence that our results are not an artifact of the asset specificity of such sectors as the power industry.

Surely the inference presented so far relies on the interpretation of our composite scores, 
and this is ultimately up to debate. So, to strengthen the validity of our findings, we also present the results of the individual survey responses. The results for the five single response variables are reported in Table 5. The coefficients show that firms' high emission levels are positively correlated with all the five sets of opinions, meaning that highly polluting firms support the ETS as long as its costs are contained. However, if asked about the EU ETS long-term implications they would reconsider their carbon investments and/or relocate. Sectors' high $\mathrm{CO}_{2}$ levels are positively correlated with opinions on maturity and - although not significantly - efficiency and are negatively correlated with opinions on relocation. Again, this follows our expectation that firms in dirtier sectors see more benefits in the EU ETS in the short run but are more opposed and, specifically, more willing to relocate if the costs from regulation rise unless they are in high-emission sectors that cannot easily move.

\section{Robustness}

The findings from the analyses of the composite scores are robust to different modeling choices and to transformations of the outcome variable ${ }^{25}$ Similarly, the results for the response-specific regressions are overall similar if we regress the responses measured in their original scales and if we correlate them with the continuous measures of firm and sector's emissions. 26

We additionally estimated the correlations between emission levels and the two scores

\footnotetext{
${ }^{25}$ Random-effect models that calculate the variance at the country level and at the country-sector level show that neither country nor sector intercepts capture much of the residual variance, and that the effects of the emission indicators remain qualitatively similar to the effects estimated in the main models. Furthermore, in additional regressions we transformed the composite scores into dichotomized variables where we assign 1 to positive scores $(>0)$, and 0 otherwise. We find that the firm- and sector-level emissions have consistent effects if we analyze these scores with probit and linear models. See Table A.6 and Table A.7 in the online Appendix available at this journal's website.

${ }^{26}$ See Table A.8 and A.9 in the online Appendix available at this journal's website.
} 
computed through our factor analysis, which in our framework constitute two latent measures of preferences for the short- versus long-term implications of the ETS. We picked 2010 as a year of 'lax' policy and 2013 as the year when the ETS became stricter (i.e., when auctioning was implemented). Our argument implies that high $\mathrm{CO}_{2}$ levels should be more positively correlated with responses related to Factor 1 in early years rather than after auctioning (2013). Vice versa, low-emission firms should better appreciate the stricter policy that started in 2013. This is precisely what we find: the coefficient for high $\mathrm{CO}_{2}$ levels is higher for the 2010 regressions of the questions loaded on Factor 1. Along similar lines, we find that low-emission firms in the year 2013 are more positive about the cost efficiency of the EU ETS compared to previous years without auctioning. ${ }^{27}$

One alternative explanation for the variation in views on the EU ETS relates to systematic individual-level differences across respondents working in high- and low-emitting firms. To assess this hypothesis, we use the original data from 2010, when questions about respondents' age and education level (i.e., school degree) were asked. The data indicate that there is no major substantive difference in the demographic characteristics of the respondents from the high- and low-emission firms, although workers in high-emission firms are overall younger ${ }^{28}$ In more systematic regression analyses of ETS positions where we control for age and education, we still find that individuals in more polluting firms and sectors are more optimistic about the state of the ETS policy in terms of current efficiency and maturity, but they are also more ready to eventually consider relocation ${ }^{29}$ Hence, the inclusion of age and

\footnotetext{
${ }^{27}$ See Table A.10 and Table A.11 in the online Appendix available at this journal's website. Note that in Table A.10 the difference between high emitters and low emitters is statistically meaningful because the confidence intervals of the coefficient estimates for the firm's GHG variables do not overlap.

${ }^{28}$ See Table A.12 in the online Appendix available at this journal's website.

${ }^{29}$ See Table A.13 in the online Appendix available at this journal's website.
} 
education as predictors of perceived characteristics of the ETS does not substantially change the overall effect of emissions on our measures of EU ETS opinions.

Similarly, a potential concern with our main results is that we miss information on difference in size across firms, mainly because we have access to data that cannot reveal the respondents' identity nor can be used at the individual response level. We address this concern in the following way and only for the year 2010, for which we have been able to access additional information. First, we identified the number of full-time employees and current-USD operating revenue volumes available from public sources, specifically firms' annual reports. Afterwards, we aggregated this information at our unit of measurement (country-sector-firm $\mathrm{CO}_{2}$ level) for the 2010 data. We then generated dummy variables that measure 'high' and 'low' levels of employees and revenue, which correspond to values above and below the sample averages, respectively. We find that, for 2010, half of the 'smaller' firms - i.e., firms with less-than-average numbers of employees and revenue - are high polluters, while half of them are not. Moreover and as expected, of the 'larger' firms more than half are high polluters, while one third of firms produce relatively low levels of pollution. To verify whether firms' size is a crucial omitted variable after all, we also ran our basic regression models adding the employee and revenue dummies. The direction of the results is consistent with our main findings, although some of the partial correlations miss statistical significance because of low statistical power given the smaller sample. We find that employee and revenue levels are statistically associated with the second factor outcome and its relevant sub-level questions regarding long-term $\mathrm{CO}_{2}$ price implications and relocation. Nonetheless, firmlevel emissions and sector-level emissions remain associated with the outcome variables as 
observed in the main regression analyses 30

Another concern one may have regarding our findings is that the simple nature of asset specificity may dominate our analysis, especially with regard to the relocation question. While we have no proxy of relocation 'capacity' per se, we investigate if, by running the factor analysis without the relocation question, we can still identify a future-looking dimension across the responses. If we did, we should be more confident that the result is not driven by ad hoc industrial characteristics related to relocation. Indeed, we find that the two dimensions emerge even without accounting for the relocation questions, still loading on the one hand on the questions on policy efficiency and maturity, and on the other hand on $\mathrm{CO}_{2}$ reductions and saliency of long-term $\mathrm{CO}_{2}$ price. Additionally, we find that the correlations between GHG levels and the predicted factor scores are consistent with our main results. ${ }^{31}$ We believe this is further evidence of the different aspects of the ETS and that firms differently support each of these aspects according to their emission levels.

If our reasoning is valid, the time-sensitive support for the EU ETS should also be observed among the early pro-policy lobbies that include finance and banking actors (Paterson, 2012). Thus, we also explore to what extent we see evidence of companies not directly covered by the EU ETS joining a coalition in favor of the policy, as suggested in our theoretical discussion. To address this question, we analyze the responses on cost-efficiency and maturity from 2013, which is the most recent of our complete surveys. The data show that individuals representing banks, consultants, and other companies without a compliance obligation under the EU ETS $(\mathrm{N}=89)$ think of the ETS as significantly more cost-effective than those working under ETS obligations $(\mathrm{N}=185)$. Specifically, the average score for individuals

\footnotetext{
${ }^{30}$ See Table A.14 in the online Appendix available at this journal's website.

${ }^{31}$ See Table $\overline{\overline{A .15}}$ and Table A.16 in the online Appendix available at this journal's website.
} 
in the financial sector on the cost-effectiveness question is 3.4 on the 1-5 scale, against 3.0 for EU ETS compliance entities. This difference corresponds to about half a standard deviation on the question, and is statistically significant at the 1.1 percent level (diff. $=-.38, \mathrm{n}=$ $272, \mathrm{t}=-2.3)$. This relationship holds also if other service providers such as consultants and representatives of carbon credit exchanges are added to the equation alongside financial traders $\sqrt[32]{2}$ This relatively positive evaluation serves as evidence that the EU ETS has over time developed a set of auxiliary supporters without compliance obligations but with vested interests in the continuation of carbon trading in Europe.

Finally, one may ask whether there are any interactive effects of firm and sector emissions. After all, it is plausible that a sector's emissions increase the perception of a firm's individual emissions, and that this may 'magnify' the impact of emission levels on opinions on the ETS. In the online Appendix available at this journal's website we report the interaction models that test whether opinions on the ETS are the product of such intersection of firmand sector's emissions ${ }^{33}$ Overall, we find that this interaction does not predict corporate opinions on the aspects of the EU ETS investigated in this paper. More specifically, the multiplicative variable Firm: high $\mathrm{CO}_{2}$ emitter $\mathrm{X}$ Sector: high $\mathrm{CO}_{2}$ emitter is not statistically significant in any of our models (the findings are similar if we use the categorical measure of firm's emissions). These results indicate a lack of evidence that the average support for the ETS - be it in reference to the lax phase or in the more stringent phase - is the byproduct of a combination of firm and sectoral emissions. Thus, we cannot say that respondents in low-emission firms are more inclined to either support or reject the characteristics of the ETS based on whether they are in cleaner or dirtier sectors. We think the null interaction

\footnotetext{
${ }^{32}$ On the maturity question, by contrast, there is no difference across the groups.

${ }^{33}$ See Table A.17
} 
may be consistent with the literature that finds that individuals' opinions on climate policy is sensitive to individual circumstances and sectoral context, but not the combination of the two (see for instance Bechtel et al., 2018).

\section{Text Analysis}

In addition to the numerical responses analyzed thus far, the Carbon Market Survey collected responses in the form of text entered by the respondents into the online form. Open-ended questions related to cap-and-trade were given to all respondents with an interest in the policy instrument, both to individuals working for companies with a compliance obligation in the EU ETS and to individuals with other jobs, such as bankers, consultants and NGO employees. In 2007-13, participants were asked to provide any comments right after being asked about the maturity and cost-effectiveness of the EU ETS ${ }^{34}$ There were in total 944 responses to this question over the nine years: 130 responses came from employees from companies with EU ETS obligations; employees of companies not covered by the EU ETS (meaning both European and non-European companies from sectors not directly regulated by the EU ETS) wrote the remaining 814.

To identify clusters of related textual replies, we employed structural topic modeling (STM) Roberts, Stewart, Tingley, Lucas, Leder-Luis, Gadarian, Albertson and Ran, 2014 Roberts, Stewart and Tingley, 2014). This approach clusters texts according to word frequencies and co-location of words within documents, with each survey response in our case serving as a document. ${ }^{35}$ We ran a dozen different models with different numbers of topics to

\footnotetext{
${ }^{34}$ Later, from 2014 onwards, the respondents were asked more generally to evaluate cap-and-trade as a climate policy tool in a separate part of the survey, using the question "Please share your view on cap-andtrade as a policy instrument for emission abatement." To avoid issues related to wording variation and to stay consistent with the years covered by our observational data, we focus only on the 2007-2013 texts.

${ }^{35}$ Note that the the 944 meaningful open answers are not representative of the full universe of EU firms, but
} 
validate the models. In general, the topics presented here were also seen in other model runs (see Tvinnereim and Fløttum, 2015). Based on a qualitative assessment of topic coherence and exclusivity, we selected a ten-topic model, from which four topics were compelling for our study: 1) allocation issues related to free versus auctioning permits (strictness of the cap); 2) theory vs. practice regarding the implementation of cap-and-trade; 3) reservation of judgment or if it is "too early to tell" whether cap-and-trade works; and 4) regulatory and political uncertainty around cap-and-trade. The most representative terms and statements for each topic are reported in the online Appendix available at this journal's website ${ }^{36}$

When contrasting responses from individuals employed at EU ETS compliance entities, we find that smaller emitters are somewhat more likely to bring up the topic related to allocation issues. As per Figure 3 (left panel), this topic is 4.2 percentage points more prevalent among small EU ETS emitters than among large EU ETS emitters, a difference that is statistically significant at the $90 \%$ level. This suggests that small emitters in particular have been unhappy with the initial allocation of the EU ETS, whereas large emitters have been less worried about issues regarding the overall cap and the free allocation. Comparing EU ETS-regulated emitters with all other respondents including consultants, bankers, and NGOs (right panel), we also find that compliance entities express more worries about regulatory and political uncertainty, all else equal. This result suggests that compliance entities put more emphasis on the potential long-haul risks of the policy. In sum, this analysis corroborates the theory that opinions on cap-and-trade vary as a function of the burden of the current policy.

that there is substantive structural variation in the firms to which these comments correspond. Furthermore, note that the volume of open comments analyzed here is similar in magnitude to the number of open answers studied in (Roberts, Stewart, Tingley, Lucas, Leder-Luis, Gadarian, Albertson and Ran, 2014).

${ }^{36}$ See Table A.18. 
What about temporal effects? In accordance with our theory, the relative size of these topics changes over time. Notably, Figure 4 shows that worries about allocation issues, including the size of the cap, decline over the years under analysis. This fits with the history of the EU ETS, where auctioning has been introduced over time as the cap has tightened.

At the same time, the topic concerning regulatory and political uncertainty has increased in importance over the years, presumably as price movements have become less predictable and more dependent on political announcements relative to fuel price movements. This also suggests an increased worry among larger emitters as regards the long-term effects of the EU ETS itself, insofar as the impacts of regulations may have stronger impacts in their future.

\section{Discussion}

This paper postulates that, far from constituting a bipolar struggle of 'government versus industry,' international climate regulations present a set of multiple interests driven by firm-level and sector-wide characteristics. Cap-and-trade, as introduced by the European Commission and a few dozen other jurisdictions worldwide, implies different costs and benefits to different types of domestic firms, and this leads to diverging interests. Specifically for the EU ETS, we argued that two dimensions should underlie corporate opinions on this international policy given its gradual implementation. One relates to the general affinity toward the ETS as it stands in its initial, more lenient phase. The other expresses concern about long-term strategy, as the effects of carbon pricing and potential plans to relocate due to carbon costs emerge.

With respect to the first dimension, we have argued that the support for the initial state of cap-and-trade is a partly opportunistic and relatively short-term approach that 
high-emission firms may be more likely to embrace. Firms may second a more feeble ETS to gain advantages over competitors in the same sector or to avoid more direct regulations, while still improving their public reputation for complying with policy. Accordingly, we have shown that higher-emitting firms are more supportive of an ETS than lower-emitting firms, keeping everything else constant.

Open responses from the Carbon Market Survey support this inference. For example, a respondent for a low-emitting company in the oil and gas sector in a Northwestern European country mentions dissatisfaction with the ETS, suggesting that "an ETS with tighter supply would be more effective in reducing emissions than the current ETS" (2007). Higher (lower) amounts of sectoral emissions also correlate with more (less) support for the capand-trade system as it is. Along these lines, one representative of a large emitter from the cement/lime/glass category states that "the EU ETS is one way to reduce emissions. On its own, it is cost-effective" (2010). Also concordant with our theory, companies in low-emission sectors systematically convey disappointment with the more lenient state of the EU ETS. In the words of a respondent from the low-emitting pulp and paper sector, the system "might be cost-effective but only if there is a GLOBAL agreement" (2011).

Regarding the long-term dimension of the policy, we argued that large polluting companies are more willing to express opposition by means of diverting investments or considering relocation as a way to escape further costs from policy adjustment. Again, the open responses confirm this logic. For instance, a representative of manufacturing in a North European country indicates that "To have effect the scheme has to be world wide. If this does not happen some businesses will not be able to pass on costs of reduction - thus forcing these companies to move production to countries not covered by any quota/emission limitation" (2007). 
The fact that firms can individually relocate is not, however, the only strategy to handle a more stringent policy. We acknowledge that some high-emission sectors are not likely to relocate, especially those that heavily rely on territorial constraints such as infrastructure and proximity to customers as for the case of the power sector. This contention is supported by the statistical findings, and is further corroborated by the statement of a representative of the power sector in central Europe who noted that while "Europe's contribution to global carbon emissions [is] getting less and less relevant, European politicians are crazy enough to think they can save the world with the EU ETS. [...] Power production can't move" (2012).

In sum, in this paper we have shown that domestic opinions on international carbon trading are connected to corporate sentiments of the status quo as well as the future of this policy and are divided across firms and sectors. For policymakers, our findings are important for at least two reasons. First, one implication is that divergent business interests over climate regulation allow governments to tailor policies in such a way that majority coalitions in favor of emission reductions may emerge. Second, our study indicates that distributional climate policies may lose legitimacy if the need for business support implies that the regulation does not engender the desired transformation of industry and the energy system.

We think these lessons are relevant to the international political economy literature, as they inform the domestic politics of international regulations and the price of international organization more broadly. Along the lines of Mattli and Woods (2009), our results suggest that so far the European carbon scheme has only partially given momentum to ambitious climate change abatement, as more polluting firms have only been inclined to embrace regulation at its lowest price. Hence, our findings point to the risk of ETS 'regulatory capture' 
by polluting firms, or the high risks of carbon leakage if no global carbon price is set.

Our paper also strengthens the thesis that large monopolistic firms can be the main standard setters of international regulatory schemes (Büthe and Mattli, 2011). While in principle the EU wishes to make the EU ETS more competitive, our data suggests that the potential losers of a more competitive EU ETS are going to fight or relocate. Consequently and in line with other works on corporate preferences and climate change politics (Levy and Kolk, 2002, Victor and House, 2006; Meckling, 2015), our paper suggests that the EU will need to choose between the demands of substantial emission reductions and the economic imperatives of incumbent firms in important emitting sectors.

Finally, the paper showed how 'policies create politics' (Pierson, 1993) in the context of international environmental schemes such as the EU ETS. Consequently, if the EU is to start working towards ambitious environmental goals, it will need to find ways to shift preferences toward policy support while adapting firms to new policy adjustments. 


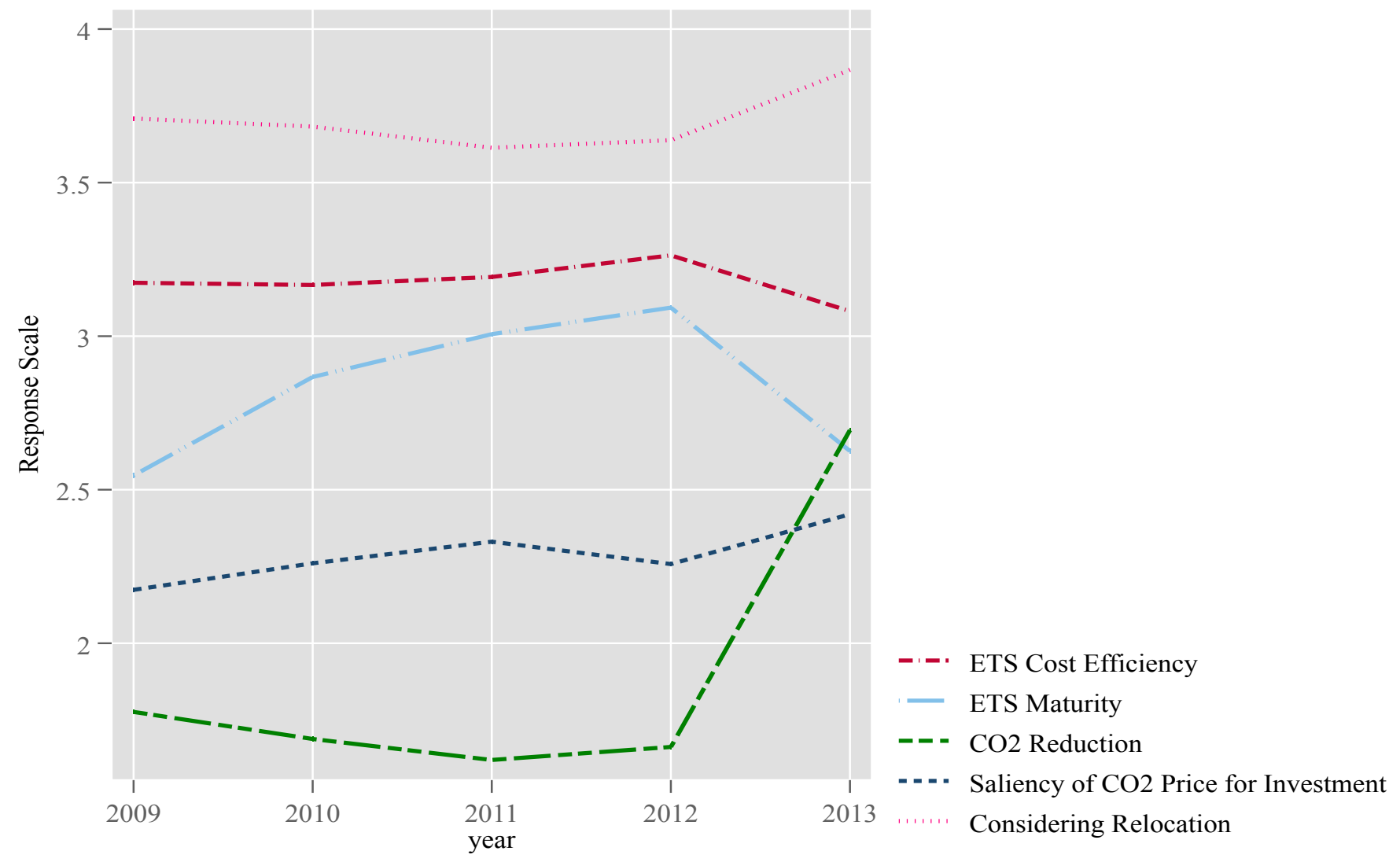

Figure 1 - Average Opinions on the EU ETS: Time Trends Across Five Main Survey Items

This figure shows the yearly trends of our five survey responses. Values are average responses measured in the original scales. 

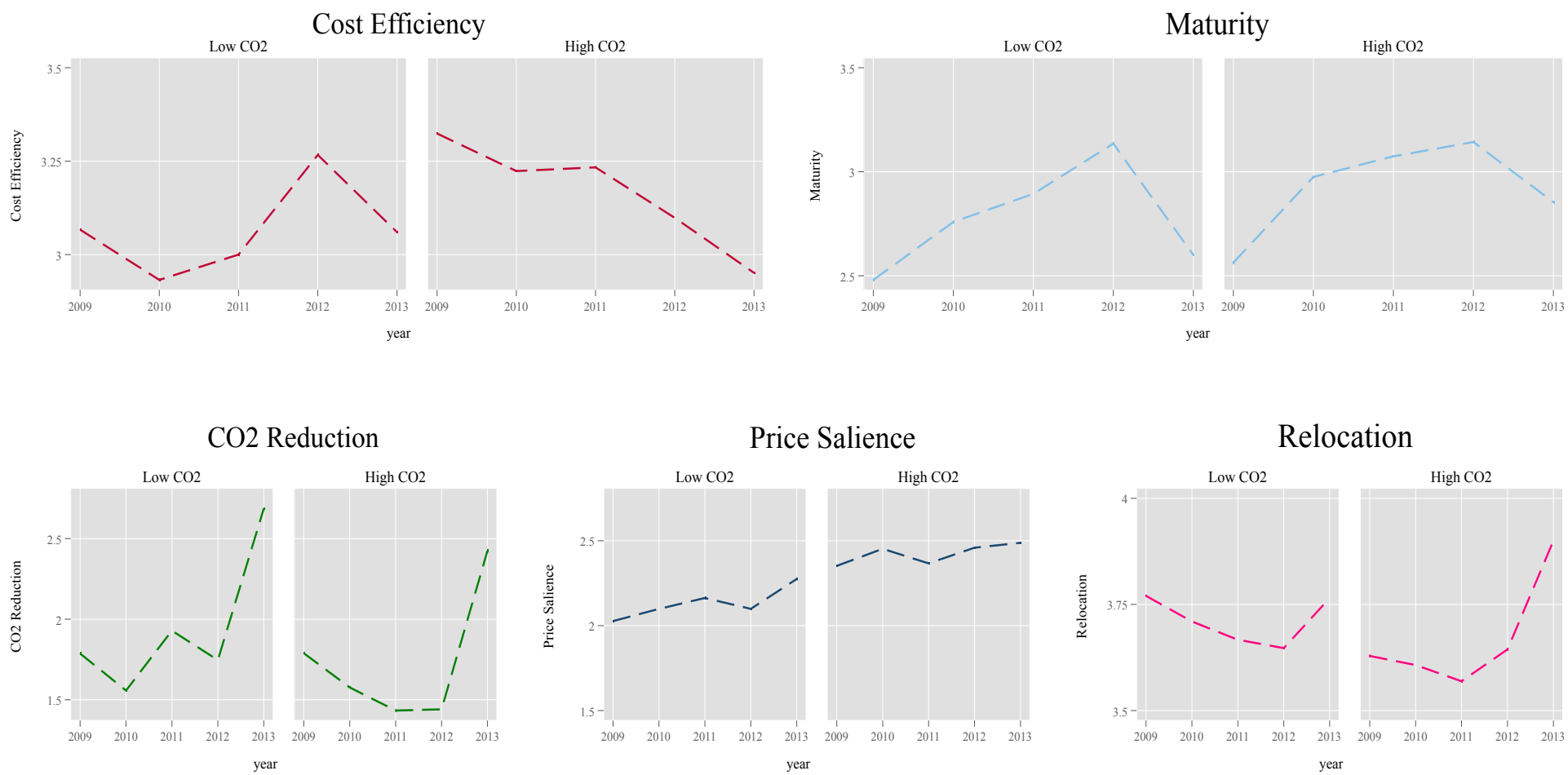

Figure 2 - Average Opinions on the EU ETS: Time Trends By Levels of Emissions

This figure shows the yearly trends in the five survey responses broken down by low-emission $(<1$ million GHG tons) and high-emission (>1 million GHG tons) firms. 

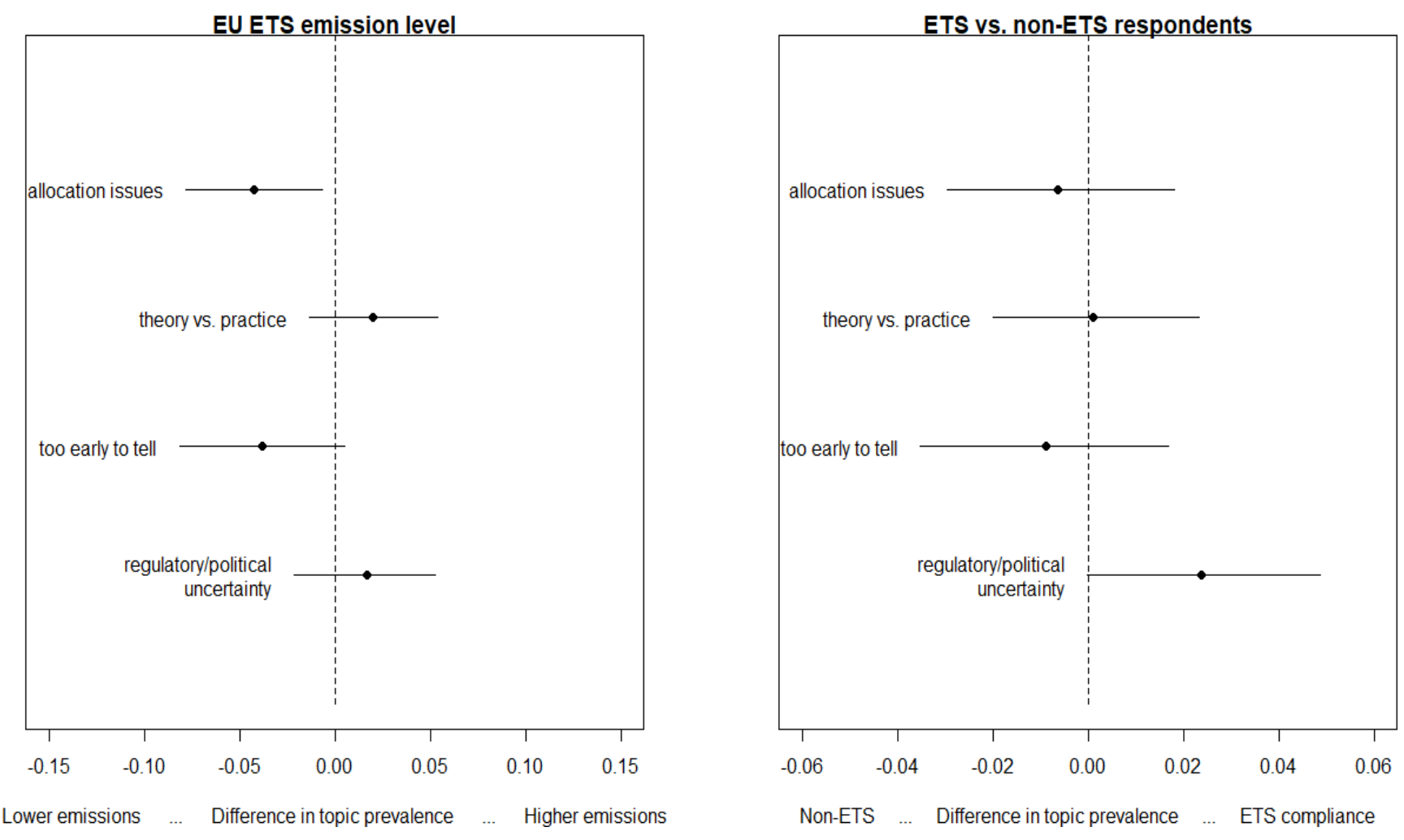

Figure 3 - Effects of ETS emission level (left panel) and ETS compliance status (right panel) on topic prevalence in responses to an open-ended question about the EU ETS

The figure displays coefficients and $90 \%$ confidence intervals for each of four selected topics from a linear regression model with year, ETS emissions (high versus low) and EU ETS status (company has a compliance obligation or not). The variables not shown on the horizontal axes (including dummies for each year) are held at their medians. Coefficients to the right of the dotted zero line indicate that respondents associated with higher emissions (left panel) or covered by the EU ETS (right panel) are more likely to bring up the given topic. Confidence intervals indicate uncertainty from both the regression model and the STM estimation process. $\mathrm{N}=944$. 


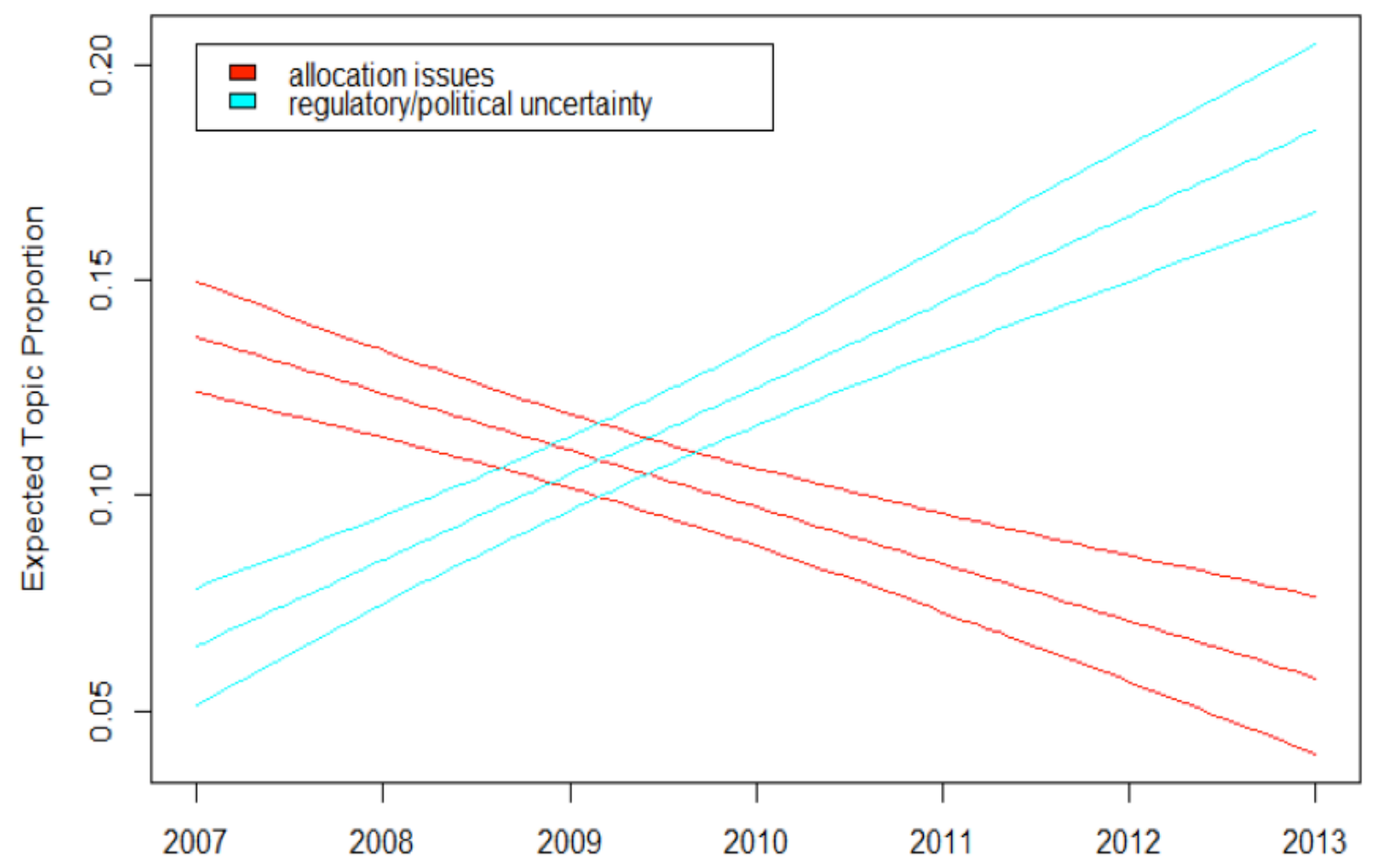

Figure 4 -Effects of time on topic prevalence in responses to an open-ended question about the EU ETS

The figure displays coefficients and $90 \%$ confidence intervals for two of the four selected topics from a linear regression model with year, ETS emissions (high versus low) and EU ETS status (company has a compliance obligation or not). $\mathrm{N}=944$. 


\begin{tabular}{c|c|c} 
& $\begin{array}{c}\text { EU ETS } \\
\text { population }\end{array}$ & $\begin{array}{c}\text { Survey } \\
\text { sample }\end{array}$ \\
\hline Covered Countries' Emissions (M tons $\mathrm{CO}_{2}$ ) & 1,939 & 1,584 \\
\hline Emissions from Covered Sectors (\% of total) & & \\
Power and Heating & 72 & 40 \\
Manufacturing and Construction & 13 & 30 \\
Mining and transport & 8 & 14 \\
Industrial Processes & 4 & 3 \\
Bunker Industry & 1 & 1 \\
Other & 3 & 12 \\
\hline
\end{tabular}

Table 1 - Distribution of $\mathrm{CO}_{2}$ across the Sample (Firms of Respondents) and the EU ETS. The 'population' statistics refer to 2012 total and sectoral EU ETS emissions of the EU-28 countries. The survey sample statistics refer to the 2009-2013 averaged emissions based on their self-reported responses in the Point Carbon survey (our calculations). Note that the survey sample includes observations with missing responses on the outcome variables $(\mathrm{N}=613)$, but excludes observations for which we do not have information on either firm emissions or sector emission $(\mathrm{N}=235)$. 


\begin{tabular}{l|c|c|c} 
& Factor 1 & Factor 2 & $\psi$ \\
\hline The EUETS is cost-effective $(\mathrm{N}=589)$ & $\mathbf{. 5 8 4}$ & -.204 & .42 \\
\hline The EU ETS is mature $(\mathrm{N}=568)$ & $\mathbf{. 5 4 7}$ & -.183 & .50 \\
\hline The EU ETS has led to reduced emissions in my company $(\mathrm{N}=561)$ & .436 & .398 & .52 \\
\hline The CO price is salient for investments in my industry $(\mathrm{N}=609)$ & .355 & $\mathbf{. 5 3 4}$ & .47 \\
\hline The EU ETS has led my firm to move or consider moving $(\mathrm{N}=601)$ & -.207 & $\mathbf{. 6 9 4}$ & .37
\end{tabular}

Table 2 - Factor analysis of five survey questions about the EU ETS. The factor model was rotated orthogonally to produce the lowest cross-loadings, but the results obtained with oblique rotation are substantively similar. Bold indicates the more concentrated loadings that are above a value of .5 . 


\begin{tabular}{|c|c|c|c|c|}
\hline & \multicolumn{2}{|c|}{ Factor 1} & \multicolumn{2}{|c|}{ Factor 2} \\
\hline Firm: high $\mathrm{CO}_{2}$ emitter & $\begin{array}{c}0.582^{* * *} \\
(0.202)\end{array}$ & & $\begin{array}{c}0.528^{* * *} \\
(0.116)\end{array}$ & \\
\hline Sector: high $\mathrm{CO}_{2}$ emitter & $\begin{array}{c}0.447^{* *} \\
(0.161)\end{array}$ & & $\begin{array}{c}-0.354^{* * *} \\
(0.089)\end{array}$ & \\
\hline Firm: $\mathrm{CO}_{2}$ emissions & & $\begin{array}{c}0.227^{* * *} \\
(0.061)\end{array}$ & & $\begin{array}{c}0.198^{* * *} \\
(0.050)\end{array}$ \\
\hline Sector: $\mathrm{CO}_{2}$ emissions & & $\begin{array}{c}0.004^{* * *} \\
(0.001)\end{array}$ & & $\begin{array}{c}-0.003^{* * *} \\
(0.001)\end{array}$ \\
\hline Unit labor cost: high & 0.052 & 0.032 & $-0.370 *$ & $-0.363^{*}$ \\
\hline & $(0.175)$ & $(0.176)$ & $(0.194)$ & $(0.196)$ \\
\hline Log GDP per capita & 1.646 & 1.565 & $3.446^{* *}$ & $3.609 * * *$ \\
\hline & $(1.748)$ & $(1.812)$ & $(1.221)$ & $(1.026)$ \\
\hline Regulatory quality & -1.488 & -1.367 & 0.138 & 0.053 \\
\hline & $(1.094)$ & $(1.089)$ & $(0.905)$ & $(0.877)$ \\
\hline Government ideology & -0.018 & -0.008 & 0.047 & 0.055 \\
\hline & $(0.050)$ & $(0.049)$ & $(0.063)$ & $(0.063)$ \\
\hline Fossil fuels fiscal support & 0.011 & 0.017 & $0.040 * *$ & $0.041^{* *}$ \\
\hline & $(0.015)$ & $(0.015)$ & $(0.017)$ & $(0.017)$ \\
\hline Constant & $\begin{array}{l}-16.450 \\
(17.413)\end{array}$ & $\begin{array}{l}-15.460 \\
(18.133)\end{array}$ & $\begin{array}{c}-36.462^{* * * *} \\
(12.421)\end{array}$ & $\begin{array}{c}-38.772^{* * *} \\
(10.347)\end{array}$ \\
\hline Country dummies & yes & yes & yes & yes \\
\hline Year dummies & yes & yes & yes & yes \\
\hline Observations & 362 & 362 & 362 & 362 \\
\hline$R^{2}$ & 0.170 & 0.182 & 0.163 & 0.180 \\
\hline
\end{tabular}

Table 3 - Attitudes toward the EU cap-and-trade system among European firms, 2009-2013. The table reports the coefficients of a linear model. The outcome variables in Columns 1-2 and Columns 3-4 are the continuous composite scores on Factor 1 and Factor 2, respectively. Clustered standard errors are in parentheses. Coefficients of year and country fixed effects are omitted. ${ }^{* * *} \mathrm{p}<0.01,{ }^{* *} \mathrm{p}<0.05,{ }^{*} \mathrm{p}<0.1$. 


\begin{tabular}{|c|c|c|c|c|}
\hline \multirow{2}{*}{ Firm: high $\mathrm{CO}_{2}$ emitter } & \multicolumn{2}{|c|}{ Factor 1} & \multicolumn{2}{|c|}{ Factor 2} \\
\hline & & $\begin{array}{c}0.589^{* * *} \\
(0.101)\end{array}$ & & $\begin{array}{c}0.621^{* *} \\
(0.190)\end{array}$ \\
\hline Firm: $0.5-1.0$ GHG Mt & $\begin{array}{c}0.321 \\
(0.224)\end{array}$ & & $\begin{array}{c}0.195 \\
(0.304)\end{array}$ & \\
\hline Firm: $1.0-5.0 \mathrm{GHG} \mathrm{Mt}$ & $\begin{array}{c}0.420 \\
(0.249)\end{array}$ & & $\begin{array}{c}0.304 \\
(0.233)\end{array}$ & \\
\hline Firm: $5.0-10.0 \mathrm{GHG} M t$ & $\begin{array}{c}0.725^{* *} \\
(0.305)\end{array}$ & & $\begin{array}{c}0.800^{* * *} \\
(0.260)\end{array}$ & \\
\hline Firm: $>10$ GHG Mt & $\begin{array}{c}0.895^{* * * *} \\
(0.233)\end{array}$ & & $\begin{array}{c}0.786^{* * *} \\
(0.222)\end{array}$ & \\
\hline Sector: high $\mathrm{CO}_{2}$ emitter & $\begin{array}{c}0.415^{* *} \\
(0.161)\end{array}$ & & $\begin{array}{c}-0.375^{* * *} \\
(0.090)\end{array}$ & \\
\hline Sector: Power and Heating & & $\begin{array}{c}0.419^{* * *} \\
(0.111)\end{array}$ & & $\begin{array}{c}-0.573^{* * *} \\
(0.139)\end{array}$ \\
\hline Sector: Metals & & $\begin{array}{c}0.230 \\
(0.181)\end{array}$ & & $\begin{array}{l}0.348^{*} \\
(0.163)\end{array}$ \\
\hline Sector: Oil and Gas & & $\begin{array}{l}-0.138 \\
(0.154)\end{array}$ & & $\begin{array}{c}-0.638^{* * *} \\
(0.160)\end{array}$ \\
\hline Sector: Construction & & $\begin{array}{c}-0.397 * * * \\
(0.080)\end{array}$ & & $\begin{array}{c}0.305^{* *} \\
(0.114)\end{array}$ \\
\hline Sector: Chemicals & & $\begin{array}{l}-0.260 \\
(0.185)\end{array}$ & & $\begin{array}{c}0.135 \\
(0.111)\end{array}$ \\
\hline Sector: Aviation & & $\begin{array}{c}-1.008^{* * *} \\
(0.188)\end{array}$ & & $\begin{array}{c}-1.064^{* * *} \\
(0.222)\end{array}$ \\
\hline Sector: Food & & $\begin{array}{c}-0.715^{* *} \\
(0.228)\end{array}$ & & $\begin{array}{c}0.352^{* *} \\
(0.101)\end{array}$ \\
\hline Sector unit labor cost: high & $\begin{array}{c}0.044 \\
(0.161)\end{array}$ & $\begin{array}{l}-0.204 \\
(0.110)\end{array}$ & $\begin{array}{c}-0.393^{*} \\
(0.199)\end{array}$ & $\begin{array}{l}-0.104 \\
(0.208)\end{array}$ \\
\hline Country: Log GDP per capita & $\begin{array}{c}1.787 \\
(1.868)\end{array}$ & $\begin{array}{l}1.549 \\
(0.844)\end{array}$ & $\begin{array}{c}3.678^{* * *} \\
(1.143)\end{array}$ & $\begin{array}{c}2.471 \\
(1.488)\end{array}$ \\
\hline Country: Regulatory quality & $\begin{array}{l}-1.503 \\
(1.135)\end{array}$ & $\begin{array}{l}-0.979 \\
(1.047)\end{array}$ & $\begin{array}{c}0.040 \\
(0.883)\end{array}$ & $\begin{array}{l}-0.214 \\
(0.600)\end{array}$ \\
\hline Country: Government ideology & $\begin{array}{l}-0.008 \\
(0.049)\end{array}$ & $\begin{array}{c}0.029 \\
(0.063)\end{array}$ & $\begin{array}{c}0.056 \\
(0.065)\end{array}$ & $\begin{array}{c}0.017 \\
(0.066)\end{array}$ \\
\hline Country: Fossil fuels fiscal support & $\begin{array}{c}0.014 \\
(0.014)\end{array}$ & $\begin{array}{c}0.029 \\
(0.033)\end{array}$ & $\begin{array}{c}0.040^{* *} \\
(0.018)\end{array}$ & $\begin{array}{c}0.041 \\
(0.040)\end{array}$ \\
\hline Constant & $\begin{array}{l}-17.978 \\
(18.680)\end{array}$ & $\begin{array}{r}-15.462 \\
(8.638)\end{array}$ & $\begin{array}{c}-38.827^{* * *} \\
(11.742)\end{array}$ & $\begin{array}{l}-25.877 \\
(15.057)\end{array}$ \\
\hline Country dummies & yes & yes & yes & yes \\
\hline Year dummies & yes & yes & yes & yes \\
\hline $\begin{array}{l}\text { Observations } \\
\mathrm{R}^{2}\end{array}$ & $\begin{array}{c}362 \\
0.190\end{array}$ & $\begin{array}{c}366 \\
0.206\end{array}$ & $\begin{array}{c}362 \\
0.188\end{array}$ & $\begin{array}{c}366 \\
0.248\end{array}$ \\
\hline
\end{tabular}

Table 4 - Attitudes toward the EU cap-and-trade system among European firms, 2009-2013: Disaggregated Results. The table reports the coefficients of a linear model. The outcome variable in Columns 1-2 and Columns 3-4 are the continuous composite scores on Factor 1 and Factor 2, respectively. The reference group for firm emissions (column 1 and 3) is Firm: 0.0 - 0.5 GHG Mt. The reference group for sector (columns 2 and 4) is Sector: Pulp and Paper. Clustered standard errors are in parentheses. Coefficients of year and country fixed effects are omitted. ${ }^{* * *} \mathrm{p}<0.01,{ }^{* *} \mathrm{p}<0.05,{ }^{*} \mathrm{p}<0.1 . \quad 47$ 


\begin{tabular}{|c|c|c|c|c|c|}
\hline & $\begin{array}{c}\text { EU ETS is } \\
\text { Cost efficient }\end{array}$ & $\begin{array}{l}\text { EU ETS } \\
\text { is Mature }\end{array}$ & $\begin{array}{c}\text { ETS-caused } \\
\mathrm{CO}_{2} \text { Reductions }\end{array}$ & $\begin{array}{c}\mathrm{CO}_{2} \text { Price } \\
\text { Salience }\end{array}$ & $\begin{array}{c}\text { Considering } \\
\text { Relocation }\end{array}$ \\
\hline \multirow{2}{*}{ Firm: high $\mathrm{CO}_{2}$ emitter } & $0.315^{*}$ & $0.233^{*}$ & $0.544^{* * *}$ & $0.655^{* * *}$ & $0.381^{*}$ \\
\hline & $(0.187)$ & $(0.141)$ & $(0.144)$ & $(0.185)$ & $(0.204)$ \\
\hline \multirow[t]{2}{*}{ Sector: high $\mathrm{CO}_{2}$ emitter } & 0.109 & $0.352^{*}$ & 0.131 & 0.110 & $-0.643^{* * *}$ \\
\hline & $(0.149)$ & $(0.186)$ & $(0.114)$ & $(0.130)$ & $(0.181)$ \\
\hline \multirow[t]{2}{*}{ Unit labor cost: high } & 0.025 & -0.042 & $-0.300^{* *}$ & -0.205 & -0.333 \\
\hline & $(0.225)$ & $(0.194)$ & $(0.145)$ & $(0.200)$ & $(0.218)$ \\
\hline \multirow[t]{2}{*}{ Log GDP per capita } & -2.018 & 0.722 & $3.085^{*}$ & $3.717^{* * *}$ & 1.278 \\
\hline & $(2.037)$ & $(2.926)$ & $(1.825)$ & $(1.169)$ & $(1.730)$ \\
\hline \multirow[t]{2}{*}{ Regulatory quality } & 1.455 & -0.396 & 0.289 & $-1.995^{*}$ & 1.546 \\
\hline & $(1.525)$ & $(2.076)$ & $(1.151)$ & $(1.167)$ & $(1.218)$ \\
\hline \multirow[t]{2}{*}{ Government ideology } & 0.002 & 0.124 & $0.151^{* *}$ & -0.043 & -0.055 \\
\hline & $(0.065)$ & $(0.077)$ & $(0.064)$ & $(0.045)$ & $(0.077)$ \\
\hline \multirow[t]{2}{*}{ Fossil fuels fiscal support } & $0.038 * *$ & $0.094^{* * *}$ & 0.021 & $0.139 * * *$ & $0.063^{* * *}$ \\
\hline & $(0.017)$ & $(0.023)$ & $(0.014)$ & $(0.051)$ & $(0.019)$ \\
\hline \multirow[t]{2}{*}{ Constant } & 18.841 & -9.096 & $-34.179^{*}$ & $-36.976^{* * *}$ & -15.233 \\
\hline & $(19.975)$ & $(29.431)$ & $(18.486)$ & $(11.763)$ & $(17.786)$ \\
\hline \multirow{2}{*}{$\begin{array}{l}\text { Country dummies } \\
\text { Year dummies }\end{array}$} & yes & yes & yes & yes & yes \\
\hline & yes & yes & yes & yes & yes \\
\hline Observations & 427 & 412 & 406 & 441 & 419 \\
\hline Log-likelihood & -272.19 & -199.91 & -251.13 & -256.57 & -201.17 \\
\hline
\end{tabular}

Table 5 - Attitudes toward the EU cap-and-trade system among European firms, 2009-2013: Individual survey responses. The table reports the coefficients of probit models. The outcome variables correspond to each of the five selected survey items, as indicated. Clustered standard errors are in parentheses. Coefficients of year and country fixed effects are omitted. $* * * \mathrm{p}<0.01$, $* * \mathrm{p}<0.05, * \mathrm{p}<0.1$. 


\section{References}

Ambec, S., Coheny, M. A., Elgiez, S. and Lanoie, P. (2013), 'The porter hypothesis at 20: Can environmental regulation enhance innovation and competitiveness?', Review of Environmental Economics and Policy 7(1), 2-22.

Armingeon, K., Careja, R., Potolidis, P., Gerber, M. and Weisstanner, D. (2015), Comparative political data set 1990-2013., Technical report, Bern, Switzerland: Institute of Political Science, University of Berne.

Auld, G., Bernstein, S. and Cashore, B. (2008), 'The new corporate social responsibility', Annual Review of Enviornment and Resources 33, 413-435.

Baldwin, R. E. and Forslid, R. (2010), 'Trade liberalization with heterogeneous firms', Review of Development Economics 14(2), 161-176.

Bechtel, M. M., Genovese, F. and Scheve, K. F. (2018), 'Interests, norms, and support for the provision of global public goods: The case of climate cooperation.', British Journal of Political Science Forthcoming.

Bernauer, T., Böhmelt, T. and Koubi, V. (2013), 'Is there a democracy-civil society paradox in global environmental governance', Global Environmental Politics 13(1), 88-107.

Böhmelt, T. (2013), 'Civil society lobbying and countries' climate change policies: A matching approach', Climate Policy 13(6), 698-717.

Brooks, S. M. and Kurtz, M. J. (2007), 'Capital, trade, and the political economies of reform', American Journal of Political Science 51(4), 703-720.

Büthe and Mattli, W. (2011), The New Global Rulers: The Privatization of Regulation in the World Economy, Princeton: Princeton University Press.

Cao, X. and Prakash, A. (2010), 'Trade competition and domestic pollution: A panel study, 19802003', International Organization 64(3), 481-503.

Damania, R., Fredriksson, P. G. and List, J. A. (2003), 'Trade liberalization, corruption, and environmental policy formation: Theory and evidence', Journal of Environmental Economics and Management 46(3), 490-512.

De Massis, A., Sharma, P., Chua, J. and Chrisman, J. (2012), Family Business Studies: An Annotated Bibliography, Edward Elgar Publishing.

Dimantchev, E., Lawson, A., Ferdinand, M., Chai, H., Nordeng, A., Fjellheim, H., Schjølset, S. and Melum, F. (2013), 'Carbon 2013: At a tipping point'.

Fernandez, R. and Rodrik, D. (1991), 'Resistance to reform: Status quo bias in the presence of individual-specific uncertainty', American Economic Review 81(5), 1146-55.

Genovese, F., Kern, F. and Martin, C. (2017), 'Policy alteration: Rethinking diffusion processes when policies have alternatives.', International Studies Quarterly 61(2), 236-252.

Hacker, J. and Pierson, P. (2002), 'Business power and social policy: Employers and the formation of the american welfare state', Politics \& Society 30, 277-325.

Helpman, E., Melitz, M. J. and Yeaple, S. R. (2004), 'Export versus fdi with heterogeneous firms', American Economic Review 94(1), 300-316. 
Kim, I. S. (2017), 'Political cleavages within industry: Firm-level lobbying for trade liberalization', American Political Science Review 111(1), 1-20.

Kim, S. E., Urpelainen, J. and Yang, J. (2016), 'Electric utilities and american climate policy: Lobbying by expected winners and losers', Journal of Public Policy 36(2), 251-175.

Levy, D. L. and Kolk, A. (2002), 'Strategic responses to global climate change. conflicting pressures on multinationals in the oil industry.', Business and Politics 4, 275-300.

Lyon, T. P. and Maxwell, J. W. (2008), 'Corporate social responsibility and the environment: A theoretical perspective', Review of Environmental Economics and Policy 2(2), 240-260.

Mattli, W. and Woods, N. (2009), The Politics of Global Regulation, Princeton, NJ: Princeton University Press.

Meckling, J. (2011), Carbon coalitions: Business, climate politics, and the rise of emissions trading, MIT Press.

Meckling, J. (2015), 'Oppose, support, or hedge? distributional effects, regulatory pressure, and business strategy in environmental politics', Global Environmental Politics .

Meckling, J., Kelsey, N., Biber, E. and Zysman, J. (2015), 'Winning coalitions for climate policy', Science 349(1170).

Murphy, D. D. (2004), Dynamics of regulatory change: How globalization affects national regulatory policies, London: University of California Press, chapter The business dynamics of global regulatory competition, pp. 84-117.

Olson, M. (1965), The logic of collective action: Public goods and the theory of interest groups, Harvard University Press.

Ostrom, E. (2010), 'Polycentric systems for coping with collective action and global environmental change', Global Environmental Change 20(4), 550-557.

Paterson, M. (2012), 'Who and what are carbon markets for? politics and the development of climate policy', Climate Policy 12, 82-97.

Perkins, R. and Neumayer, E. (2012), 'Does the 'california effect' operate across borders? trading- and investing-up in automobile emission standards', Journal of European Public Policy 19(2), 217-237.

Pierson, P. (1993), 'When effect becomes cause: Policy feedback and political change', World Politics 45(4), 595-628.

Roberts, M. E., Stewart, B. M. and Tingley, D. (2014), 'STM: R Package for Structural Topic Models', Journal of Statistical Software .

Roberts, M. E., Stewart, B. M., Tingley, D., Lucas, C., Leder-Luis, J., Gadarian, S. K., Albertson, B. and Ran, D. G. (2014), 'Structural topic models for open-ended survey responses', American Journal of Political Science 58(4), 1064-1082.

Røine, K., Tvinnereim, E. and Hasselknippe, H. (2008), 'Carbon 2008: Post-2012 is now.', Point Carbon Annual Survey Report. 11.

Szakonyi, D. and Urpelainen, J. (2014), 'Who benefits from economic reform? firms and distributive politics', Journal of Politics 76(3), 841-858. 
Tvinnereim, E. and Fløttum, K. (2015), 'Explaining topic prevalence in answers to open-ended survey questions about climate change', Nature Climate Change 5, 744-747.

Urpelainen, J. (2010), 'Regulation under economic globalization', International Studies Quarterly 54(4), 1099-1121.

Venkatachalam, I. (2008), 'Behavioral economics for environmental policy', Ecological Economics 67, 640-645.

Victor, D. G. and House, J. C. (2006), 'BP's Emissions Trading Scheme', Energy Policy 34, 21002112 .

Whaller, N. and Whitehead, B. (1994), 'It's not easy being green.', Harvard Business Review $\mathbf{7 2}(3), 46-52$. 